\title{
Formation of phosphonates and pyrophosphates in the reactions of chlorophosphate esters with strong organic bases
}

\author{
K V P PAVAN KUMAR, K PRAVEEN KUMAR, M VIJJULATHA and \\ K C KUMARA SWAMY* \\ School of Chemistry, University of Hyderabad, Hyderabad 500 046, India \\ e-mail:kckssc@uohyd.ernet.in
}

MS received 27 July 2004; revised 25 October 2004

\begin{abstract}
The compounds $\mathrm{S}\left(6-t-\mathrm{Bu}-4-\mathrm{Me}-\mathrm{C}_{6} \mathrm{H}_{2} \mathrm{O}\right)_{2} \mathrm{P}(\mathrm{O}) \mathrm{Cl}(\mathbf{1}), \mathrm{CH}_{2}\left(6-t-\mathrm{Bu}-4-\mathrm{Me}-\mathrm{C}_{6} \mathrm{H}_{2} \mathrm{O}\right)_{2} \mathrm{P}(\mathrm{O}) \mathrm{Cl}(2)$ and $\left(2,2^{\prime}-\mathrm{C}_{20} \mathrm{H}_{12} \mathrm{O}_{2}\right) \mathrm{P}(\mathrm{O}) \mathrm{Cl}$ (3) react with diazabicycloundecene (DBU) to give rise to, predominantly, the phosphonate compounds $\left[\mathrm{S}\left(6-t-\mathrm{Bu}-4-\mathrm{Me}-\mathrm{C}_{6} \mathrm{H}_{2} \mathrm{O}\right)_{2} \mathrm{P}(\mathrm{O})(\mathrm{DBU})\right]^{+}[\mathrm{Cl}]^{-}(4), \quad\left[\mathrm{CH}_{2}\left(6-t-\mathrm{Bu}-4-\mathrm{Me}-\mathrm{C}_{6} \mathrm{H}_{2} \mathrm{O}\right)_{2} \mathrm{P}(\mathrm{O})\right.$ $(\mathrm{DBU})]^{+}[\mathrm{Cl}]^{-}(\mathbf{5})$ and $\left[\left(2,2^{\prime}-\mathrm{C}_{20} \mathrm{H}_{12} \mathrm{O}_{2}\right) \mathrm{P}(\mathrm{O})(\mathrm{DBU})\right]^{+}[\mathrm{Cl}]^{-}(\mathbf{6})$. The first two compounds could be isolated in the pure state. In analogous reactions of $\mathbf{1}$ and $\mathbf{2}$ with diazabicyclononene (DBN) or N-methyl imidazole, only the pyrophosphates $\left[\mathrm{S}\left(6-t-\mathrm{Bu}-4-\mathrm{Me}-\mathrm{C}_{6} \mathrm{H}_{2} \mathrm{O}\right)_{2} \mathrm{P}(\mathrm{O})\right]_{2} \mathrm{O}(7)$ and $\left[\mathrm{CH}_{2}\left(6-t-\mathrm{Bu}-4-\mathrm{Me}-\mathrm{C}_{6} \mathrm{H}_{2} \mathrm{O}\right)_{2} \mathrm{P}(\mathrm{O})\right]_{2} \mathrm{O}(\mathbf{8})$ could be isolated, although the reaction mixture showed several other compounds in the phosphorus NMR. A possible pathway for the formation of phosphonate salts is proposed. The X-ray crystal structures of $\mathbf{4 , 7}$ and $\mathbf{8}$ are also discussed.
\end{abstract}

Keywords. Phosphonate salts; pyrophosphate esters; X-ray crystal structure.

\section{Introduction}

Nucleophilic substitution reactions of chlorophosphates are most often carried out in the presence of a base. In the absence of the base, this reaction will be slow and sometimes the base itself acts as a nucleophilic catalyst. The mechanism of rate enhancement (nucleophilic catalysis) of the nucleophilic substitution at phosphorus is commonly interpreted by two consecutive $S_{N} 2(P)$ reactions (scheme 1$)^{1-3}$ The leaving group $\mathrm{X}$ is substituted by the nucleophilic catalyst (Cat; can be N-methyl imidazole, imidazole or other bases) leading to a very reactive intermediate (I). The nucleophile then reacts with this intermediate giving the product. Although a species of type $\mathbf{I}$ has never been detected when the mixture of alcohol and catalyst was added to chlorophosphates, it is identified by NMR in the absence of alcohol. In the reaction of $(\mathrm{RO})\left(\mathrm{RCH}_{2} \mathrm{O}\right) \mathrm{P}(\mathrm{O}) \mathrm{Cl}$ with the catalyst (Cat), formation of betaine III is observed and is assumed to occur via the intermediate $\mathbf{I I}^{4}$. In the reaction of $(\mathrm{EtO})_{2} \mathrm{P}(\mathrm{O}) \mathrm{Cl}$ with $\mathrm{N}$-methyl imidazole, Corriu and coworkers have identified three products (IVVI); salts IV-V (not isolated) are similar to II and III $^{2}$. We have been interested in identifying/isolat-

\footnotetext{
*For correspondence
}

ing intermediates of types I-III. One of the bases used by earlier workers was 1,8-diazabicyclo(5.4.0) undec-7-ene (DBU), but in a preliminary study we showed that this base could lead to phosphonate salts instead of betaines of type $\mathbf{I}^{5}$. Since such a product was never reported prior to our work, we were curious to know whether this feature is common for other chlorophosphate esters also and hence we have extended this study. The results are reported here.

We have chosen, primarily, DBU, DBN [1,5diazabicyclo(4.3.0)non-5-ene] and $\mathrm{N}$-methyl imidazole, all with two nitrogen atoms as bases and compounds $1-\mathbf{3}^{5-8}$ as phosphorus substrates.

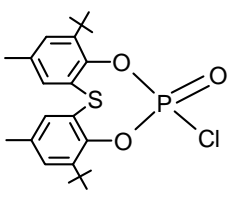

$1[\delta(P):-8.2]$

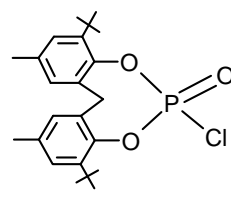

$2[\delta(P):-3.4]$

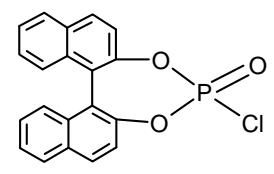

$3[\delta(P): 11.1]$

\section{Experimental section}

Chemicals were procured from Aldrich/Fluka or local manufacturers; they were purified when required. Solvents were purified according to standard proce- 
(a)

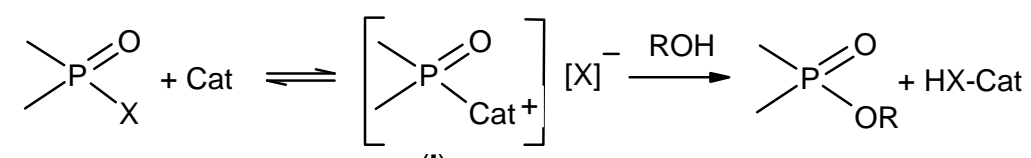

(I)

(b)

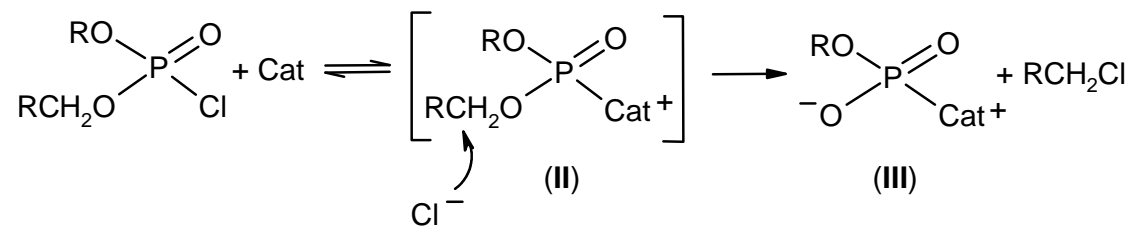<smiles></smiles>

(IV)<smiles></smiles>

$\left[(\mathrm{EtO})_{2} \mathrm{P}(\mathrm{O})\right]_{2} \mathrm{O}$

(VI)

Scheme 1.

dures. ${ }^{9}$ All reactions, unless stated otherwise, were performed under dry nitrogen atmosphere. ${ }^{1} \mathrm{H}$ and ${ }^{31} \mathrm{P}\{\mathrm{H}\}$ NMR spectra were recorded on a Bruker 200 or $400 \mathrm{MHz}$ spectrometer in $\mathrm{CDCl}_{3}$, with shifts referenced to $\mathrm{SiMe}_{4}(\delta=0)$ or $85 \% \mathrm{H}_{3} \mathrm{PO}_{4}(\delta=0)$. Elemental analyses were carried out on a Thermo Finnigan EA1112 analyser.

\subsection{Synthesis of [S(6-t-Bu-4-Me- $\left.\mathrm{C}_{6} \mathrm{H}_{2} \mathrm{O}\right)_{2} \mathrm{P}(\mathrm{O})$ $(\mathrm{DBU})]^{+}[\mathrm{Cl}]^{-}(\mathbf{4})$}

To a stirred solution of $\mathrm{S}\left(6-t-\mathrm{Bu}-4-\mathrm{Me}-\mathrm{C}_{6} \mathrm{H}_{2} \mathrm{O}\right)_{2}$ $\mathrm{P}(\mathrm{O}) \mathrm{Cl}^{6}$ (1) $(0.84 \mathrm{~g}, 1.90 \mathrm{mmol})$ in toluene $(20 \mathrm{ml})$ was added DBU $(0.29 \mathrm{~g}, 1.90 \mathrm{mmol})$ dropwise over a period of $10 \mathrm{~min}$ at room temperature. After stirring overnight, most of the solvent was removed in vacuo and the compound crystallized from dichloromethane-heptane $(2: 1)$ mixture. Yield (isolated): $0.5 \mathrm{~g}(45 \%)$. m.p.: $210^{\circ} \mathrm{C}$. IR (KBr): 3410,3198 , 2955, 1641, 1427, 1265, $1224 \mathrm{~cm}^{-1}$. ${ }^{1} \mathrm{H}$ NMR: $\delta 1 \cdot 35$, $1.46\left(2 s, 18 \underline{\mathrm{H}}, \mathrm{Ar}-\mathrm{C}\left(\mathrm{CH}_{3}\right)_{3}\right), 1.90-2.00\left(m, 8 \mathrm{H}, \mathrm{CH}_{2}\right)$, $2 \cdot 27,2.31\left(2 \mathrm{~s}, 6 \mathrm{H}, \mathrm{ArCH}_{3}\right), 3 \cdot 40-3.60\left(\mathrm{~m}, 6 \mathrm{H}, \mathrm{NCH}_{2}\right)$, 7.12-7.48 (m, 4H, Ar-H), 11.3 (br, 1H, NH). ${ }^{13} \mathrm{C}$ NMR: $\delta 19 \cdot 2,19 \cdot 5,20 \cdot 7,20 \cdot 7,20 \cdot 9,21 \cdot 4,24 \cdot 0,24 \cdot 5,25 \cdot 1$, $26 \cdot 4,26 \cdot 8,29 \cdot 5,29 \cdot 9,35 \cdot 0,35 \cdot 1,38 \cdot 5,44 \cdot 3\left[{ }^{1} J(\mathrm{P}-\right.$ C) $=130 \cdot 9 \mathrm{~Hz}], 50 \cdot 4,53 \cdot 5,53 \cdot 8,124 \cdot 4,125 \cdot 1,125 \cdot 2$, $128 \cdot 1,128 \cdot 9,129 \cdot 6,130 \cdot 2,134 \cdot 7,135 \cdot 1,135 \cdot 3,148 \cdot 7$, $148 \cdot 9,149 \cdot 5,149 \cdot 6,160 \cdot 6 .{ }^{31}$ P NMR: $\delta 6 \cdot 4$. The reaction mixture also showed peaks at $\delta-12 \cdot 8(10 \%)$ and $-22.0(5 \%)$ in the ${ }^{31} \mathrm{P}$ NMR. Analysis: Calcd. for $\mathrm{C}_{30} \mathrm{H}_{44} \mathrm{ClN}_{2} \mathrm{O}_{3} \mathrm{PS}$ (after drying): $\mathrm{C}, 62 \cdot 22 ; \mathrm{H}, 7 \cdot 61$; $\mathrm{N}, 4.84 \%$; Found: C, 61.95; H, 7.38; N, 4.62\%.

The compound $\left[\mathrm{CH}_{2}\left(6-t-\mathrm{Bu}-4-\mathrm{Me}-\mathrm{C}_{6} \mathrm{H}_{2} \mathrm{O}\right)_{2} \mathrm{P}(\mathrm{O})\right.$ $(\mathrm{DBU})]^{+}[\mathrm{Cl}]^{-}(\mathbf{5})$ [m.p. $\left.220^{\circ} \mathrm{C}\right]$ was prepared similarly; its ${ }^{1} \mathrm{H}$ and ${ }^{31} \mathrm{P}$ NMR [ $\delta$ 7.2] were identical to the one we have reported earlier ${ }^{5}$. We have tried to check its identity by ${ }^{13} \mathrm{C}$ NMR also but a detailed analysis was not possible: $\delta 19 \cdot 2,19 \cdot 6,20 \cdot 8,21 \cdot 3$, $24 \cdot 0,24 \cdot 4,25 \cdot 3,26 \cdot 8,28 \cdot 9,31 \cdot 0,31 \cdot 3,32 \cdot 1,34 \cdot 6$, $34 \cdot 8,34 \cdot 9,39 \cdot 1\left[{ }^{1} J(\mathrm{PC})=126 \cdot 0 \mathrm{~Hz}\right.$, by comparing the spectrum with that for 4], 43.1, 48.8, 49.3, 52.6, $54 \cdot 4,125 \cdot 3,127 \cdot 3,127 \cdot 4,128 \cdot 2,129 \cdot 0,129 \cdot 2$, $134 \cdot 1,134 \cdot 4,135 \cdot 3,137 \cdot 8,140 \cdot 2,144 \cdot 7,161 \cdot 0$. Analysis: Calcd. for $\mathrm{C}_{31} \mathrm{H}_{46} \mathrm{ClN}_{2} \mathrm{O}_{3} \mathrm{P}: \mathrm{C}, 66.38, \mathrm{H}, 8.21$, $\mathrm{N}, 5 \cdot 00 \%$. Found: C, 66.56, H, 7.99, N, 4.31.

The reaction of $\left(2,2^{\prime}-\mathrm{C}_{20} \mathrm{H}_{12} \mathrm{O}_{2}\right) \mathrm{P}(\mathrm{O}) \mathrm{Cl}(3$, racemic) ${ }^{8}$ with DBU was conducted in THF, because of low solubility of $\mathbf{3}$ in toluene. The ${ }^{31} \mathrm{P}$ NMR spectrum showed three peaks at $\delta 5 \cdot 3(25 \%), 29 \cdot 2(30 \%)$ and $30 \cdot 4(40 \%)$ [rest $\sim 5 \%$ ]. The peaks at $\delta 29.2$ and $30 \cdot 4$ are assigned to the diasteromeric phosphonate salts $\left[\left(2,2^{\prime}-\mathrm{C}_{20} \mathrm{H}_{12} \mathrm{O}_{2}\right) \mathrm{P}(\mathrm{O})(\mathrm{DBU})\right]^{+}[\mathrm{Cl}]^{-}(\boldsymbol{6})$ by comparing them with those for the analogous aminophosphonate $\left.(+)-\left(\mathrm{C}_{20} \mathrm{H}_{12} \mathrm{O}_{2}\right) \mathrm{P}(\mathrm{O}) \mathrm{CHNHCO}_{2} \mathrm{Et}\right) \mathrm{Ph}[\delta(\mathrm{P}) 29 \cdot 5]^{10}$. A white solid with $\delta(\mathrm{P}) 5.3(>95 \%)$, that showed only the binol and DBU residues, was isolated in the reaction of 3 with DBU in the presence of $\left(\mathrm{OCH}_{2}\right.$ $\left.\mathrm{CMe}_{2} \mathrm{CH}_{2} \mathrm{O}\right) \mathrm{P}(\mathrm{O}) \mathrm{CH}(\mathrm{OH})\left(\mathrm{C}_{6} \mathrm{H}_{4}-\mathrm{OCMe}\right)$. This solid could not be purified further, but is likely to be the phosphate salt $\left(2,2^{\prime}-\mathrm{C}_{20} \mathrm{H}_{12} \mathrm{O}_{2}\right) \mathrm{P}(\mathrm{O})\left(\mathrm{O}^{-}\right)\left[\mathrm{HDBU}^{+}\right]$ formed by hydrolysis $\left[{ }^{1} \mathrm{H}\right.$ NMR shows a peak at $\delta 10 \cdot 9 ;{ }^{13} \mathrm{C}$ NMR: complicated, but no doublet due to ${ }^{1} J(\mathrm{PC})$ is observed].

2.2 Reaction of S(6-t-Bu-4-Me- $\left.\mathrm{C}_{6} \mathrm{H}_{2} \mathrm{O}\right)_{2} \mathrm{P}(\mathrm{O}) \mathrm{Cl}(\mathbf{1})$ with DBN-Preparation of the pyrophosphate ester

$\left[\mathrm{S}\left(6-t-\mathrm{Bu}-4-\mathrm{Me}-\mathrm{C}_{6} \mathrm{H}_{2} \mathrm{O}\right){ }_{2} \mathrm{P}(\mathrm{O})\right]_{2} \mathrm{O}(7)$ : To a stirred solution of $\mathbf{1}^{1}(0.85 \mathrm{~g}, 1.94 \mathrm{mmol})$ in toluene $(20 \mathrm{ml})$ was added DBN (0.24 g, $1.94 \mathrm{mmol})$ drop-wise over a 
period of $10 \mathrm{~min}$ at room temperature. After stirring overnight the solvent was removed in vacuo and the compound crystallized from dichloromethaneheptane $(2: 1)$ mixture. In this reaction we obtained the crystals of the pyrophosphate $[\mathrm{S}\{6-t-\mathrm{Bu}-4-\mathrm{Me}-$ $\left.\left.\mathrm{C}_{6} \mathrm{H}_{2} \mathrm{O}\right\}_{2} \mathrm{P}(\mathrm{O})\right]_{2} \mathrm{O}$ (7) but not of the expected compound. m.p.: $226-228^{\circ} \mathrm{C}$. IR (KBr): 2961, 2359, 1593, 1429, 1319, $1222 \mathrm{~cm}^{-1} .{ }^{1} \mathrm{H}$ NMR: $\delta 1 \cdot 39,1.46$ ( $\mathrm{s}$ each, $\left.36 \mathrm{H}, \mathrm{Ar}-\mathrm{C}\left(\mathrm{CH}_{3}\right)_{3}\right), 2 \cdot 29\left(2 s, 12 \underline{\mathrm{H}}, \mathrm{ArCH}_{3}\right), 7 \cdot 20,7 \cdot 25$ $(2 \mathrm{~s}, 8 \mathrm{H}, \mathrm{Ar}-\underline{\mathrm{H}}) .{ }^{13} \mathrm{C} \mathrm{NMR}: \delta 20 \cdot 8\left(s, \mathrm{ArCH}_{3}\right), 30 \cdot 3$ $\left(\mathrm{Ar}-\mathrm{C}\left(\mathrm{CH}_{3}\right)_{3}\right), 35 \cdot 1\left(\mathrm{Ar}-\mathrm{C}\left(\mathrm{CH}_{3}\right)_{3}\right), 124 \cdot 7,129 \cdot 9,134 \cdot 2$, 135.0, 141.6, 150.0. ${ }^{31} \mathrm{P}$ NMR: $\delta-31 \cdot 1$. Analysis: Calcd. for $\mathrm{C}_{44} \mathrm{H}_{56} \mathrm{O}_{5} \mathrm{P}_{2} \mathrm{~S}_{2}$ (after drying): $\mathrm{C}, 66.84 ; \mathrm{H}, 7.09$. Found: C, 66.95, H, 6.98\%.

Reaction using N-methyl imidazole also resulted in the isolation of 7.

The reactions of $\mathbf{2}$ and $\mathbf{3}$ with DBN and N-methyl imidazole were done similarly, but in the latter case, THF was used as the solvent. ${ }^{31} \mathrm{P}$ NMR (major peaks,

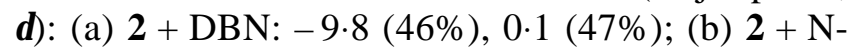
methyl imidazole: $-2 \cdot 3(65 \%),-9 \cdot 8(15 \%),-27 \cdot 6(20 \%)$; (c) $3+$ DBN: $-12.4(30 \%), 3 \cdot 2(30 \%)$ and 14.8 (30\%); (d) $3+$ N-methyl imidazole: -12.4 (70\%), $6 \cdot 1(28 \%)$. The peak at $\delta-27.6$ in (b) is due to the pyrophosphate ester $\left[\mathrm{CH}_{2}\left(6-t-\mathrm{Bu}-4-\mathrm{Me}-\mathrm{C}_{6} \mathrm{H}_{2} \mathrm{O}\right)_{2}\right.$ $\mathrm{P}(\mathrm{O})]_{2} \mathrm{O}(\mathbf{8})$ and could be isolated in $\approx 40 \%$ yield [m.p. $2766^{\circ} \mathrm{C} ;{ }^{1} \mathrm{H}$ NMR: Identical to that reported earlier ${ }^{5} ;{ }^{13} \mathrm{C}$ NMR $\delta 20 \cdot 9,30 \cdot 9,34 \cdot 6,35 \cdot 0,127 \cdot 7$, 129.4, 131.4 135.2, 141.3, 146.0. Analysis: Calcd. for $\mathrm{C}_{46} \mathrm{H}_{60} \mathrm{O}_{7} \mathrm{P}: \mathrm{C}, 70 \cdot 23 ; \mathrm{H}, 7 \cdot 63$. Found: $\mathrm{C}, 70 \cdot 43$, $\mathrm{H}, 7 \cdot 81]$. The peak at -12.4 in (c) and (d) is also assignable to the pyrophosphate ester $\left[\left(2,2^{\prime}-\mathrm{C}_{20} \mathrm{H}_{16} \mathrm{O}_{2}\right)\right.$ $\mathrm{P}(\mathrm{O})]_{2} \mathrm{O}$ on the same basis, but this compound was hydrolytically unstable [NMR evidence].

\section{$2.3 X$-ray structural analysis of 4,7 and 8}

X-ray data were collected on a Bruker AXS SMART diffractometer (for 4 and 7) or an Enraf-NoniusMACH3 (for 8; upto $2 \theta=45)$ using $\mathrm{Mo}_{\alpha}(\lambda=$ $0.71073 \AA$ ) radiation. The structures were solved by direct methods ${ }^{11}$; all non-hydrogen atoms were refined anisotropically. For the hydrogen atoms except the $\mathrm{NH}$ in $\mathbf{4}$, the riding model was used; one of the solvent hydrogen atoms in $\mathbf{4}$ was not fixed because of symmetry. In $\mathbf{8}$ although there is a void and some residual electron density in the crystal packing, we could not model it with any suitable solvent; for this compound, we had given only the crystal data before $^{5}$, but the refinement could be improved and hence structure is better now. Data were not good because of the poor crystal quality.
Crystal data: Compound 4. $\mathrm{CH}_{2} \mathrm{Cl}_{2} \cdot 1 / 2 \mathrm{C}_{6} \mathrm{H}_{5} \mathrm{CH}_{3}$ : $\mathrm{C}_{71} \mathrm{H}_{100} \mathrm{Cl}_{6} \mathrm{~N}_{4} \mathrm{O}_{6} \mathrm{P}_{2} \mathrm{~S}_{2}, \quad M=1444 \cdot 30$, triclinic, space group $P \overline{1}, a=9.521(1), b=14.310(1), c=14.533(1)$, $\alpha=93.432(1), \quad \beta=92.521(1), \quad \gamma=98.959(1), \quad V=$ 1949.6(2) $\AA^{3}, \quad Z=1, \quad \rho=1.230 \mathrm{~g} \mathrm{~cm}^{-3}, \quad F_{000}=766$, $\mu=0.364 \mathrm{~mm}^{-1}$, Data/restraints/parameters: 9130/5/ 427. $S$ (all data) $=0.981 . R$ indices $(I>2 \sigma(I))$ : $R l=0 \cdot 0535, w R 2$ (all data $)=0 \cdot 1714$. Max. $/ \mathrm{min}$. residual electron density $\left(e \AA^{-3}\right) 0 \cdot 547 /-0 \cdot 403$. Compound 7. $\mathrm{CH}_{2} \mathrm{Cl}_{2}: \mathrm{C}_{45} \mathrm{H}_{58} \mathrm{Cl}_{2} \mathrm{O}_{7} \mathrm{P}_{2} \mathrm{~S}_{2}, M=907 \cdot 87$, monoclinic, space group $P 2 / n . a=12 \cdot 509(1), b=9 \cdot 449(1)$, $c=20 \cdot 606(2), \beta=91 \cdot 003(1), V=2435 \cdot 2(3) \AA^{3}, Z=2$, $\rho=1.238 \mathrm{~g} \mathrm{~cm}^{-3}, \quad F(000)=960, \quad \mu=0.330 \mathrm{~mm}^{-1}$, Data/restraints/parameters: 5852/3/276. $S$ (all data) $=$ $1 \cdot 038, R$ indices $(I>2 \sigma(I)): R I=0.0590, w R 2$ (all data $=0 \cdot 1922$. Max./min. residual electron density $\left(e \AA^{-3}\right)$ 0.510/-0.411. Compound 8: $\mathrm{C}_{46} \mathrm{H}_{60} \mathrm{O}_{7} \mathrm{P}_{2}, M=$ 786.88, tetragonal, space group $P-4 . \quad a=b=$ 15.996(2), $\quad c=9.323(1), \quad V=2385.4(5) \AA^{3}, \quad Z=2$, $\rho=1.096 \mathrm{~g} \mathrm{~cm}^{-3}, F(000)=844, \mu=0.135 \mathrm{~mm}^{-1}$, Flack parameter (employing the WINGX programme using the twin command $\left.{ }^{12}\right)=0 \cdot 0$. Data/restraints/ parameters: $3103 / 0 / 249$. $S$ (all data) $=1 \cdot 140, R$ indices $(I>2 \sigma(I)): R I=0.0577, w R 2$ (all data) $=0.1846$. Max./min. residual electron density $\left(e \AA^{-3}\right) 0.621 /$ $0 \cdot 225$. Further details as CIF files are available from the Cambridge Crystallographic Data Centre, 12 Union Road, Cambridge CB2 1EZ, UK on request, quoting the deposition numbers CCDC 245230-245232.

\section{Results and discussion}

The reaction of 1-3 with DBU is conducted in toluene (or THF for $\mathbf{3}$ ) as the solvent. Phosphonate salts 4-6 are the major products. Compounds 4-5 could be isolated as pure solids. In the case of $\mathbf{6}$, two isomeric products $[\delta(\mathrm{P}) 29.4,30 \cdot 0$; probably diastereomeric] are formed along with another product that showed a $\delta(\mathrm{P})$ of 5.4. As mentioned in our earlier communication, assignment of structure for compound $\mathbf{5}$ could be done mainly by its downfield ${ }^{31} \mathrm{P}$ NMR chemical shift ${ }^{5}$; the ${ }^{13} \mathrm{C}$ NMR is complex and in the ${ }^{1} \mathrm{H}$ NMR, a broad resonance appeared at $\delta$ 11.48 (ascribable to $\mathrm{NH}$ proton). The spectral features of $\mathbf{4}$ were analogous to those for $\mathbf{5}$, but in this case the P-CH carbon was more readily diagnosed at $\delta 44.4\left[{ }^{1} J(\mathrm{PC})=130.0 \mathrm{~Hz}\right]$ in high-field ${ }^{13} \mathrm{C}$ NMR. For further confirmation, we have studied compound 4 by X-ray structure determination (figure 1). Attempted dehydrohalogenation of $\mathbf{4}$ in methanolic $\mathrm{NaOH}$ gave a mixture that showed two major peaks (total 

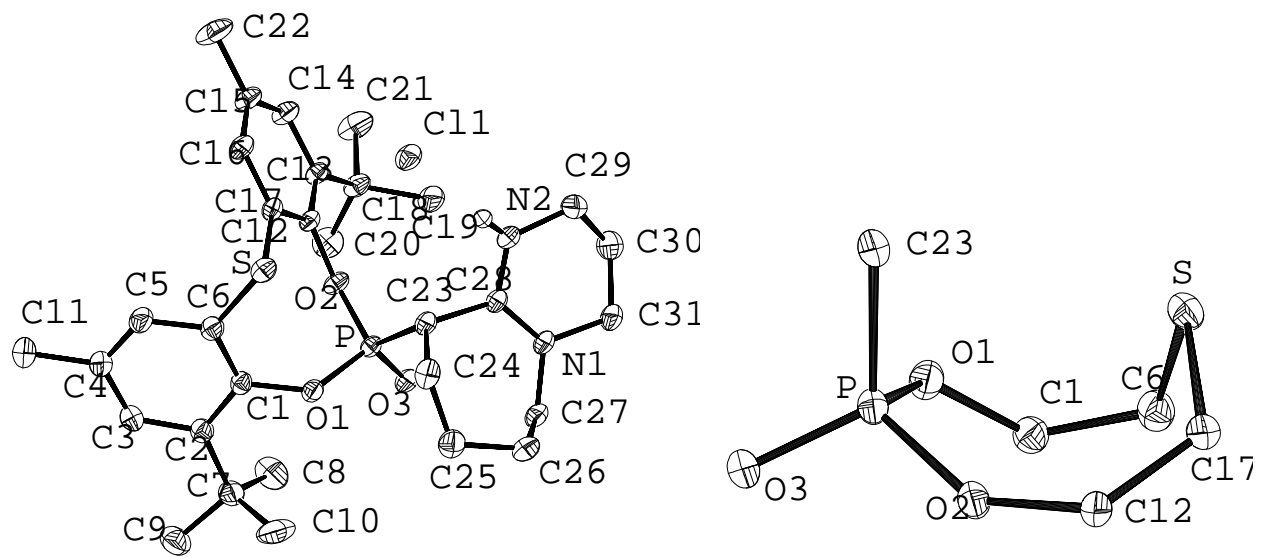

Figure 1. An ORTEP drawing of 4. $\mathrm{CH}_{2} \mathrm{Cl}_{2} \cdot 1 / 2 \mathrm{C}_{6} \mathrm{H}_{5} \mathrm{CH}_{3}$. solvent molecules are omitted. On the right hand side is shown the conformation of the eight-membered phosphocin ring. Selected bond distances $(\AA)$ : $\mathrm{P}-\mathrm{O}(1)$ 1.583(2), P-O(2) 1.568(2), P-O(3) 1.460(2), P-C(23) $1 \cdot 822(3), \mathrm{N}(1)-\mathrm{C}(28) 1 \cdot 328(3), \mathrm{N}(2)-\mathrm{C}(28) 1 \cdot 303(3)$. Hydrogen bond parameters for $\mathrm{N}(2)-$ $\mathrm{HN}(2)-\mathrm{Cl}(1): 0 \cdot 72(3), 2 \cdot 39(3)$ and $3 \cdot 109(3) \AA$ and $171(3)^{\circ}$.

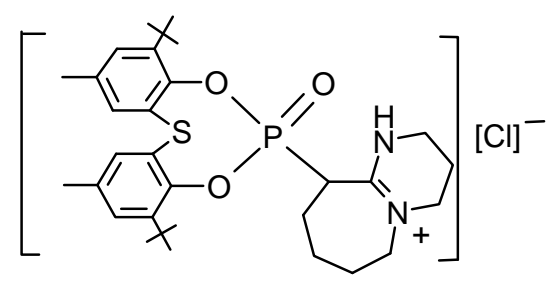

$4[\delta(P): 6.4]$

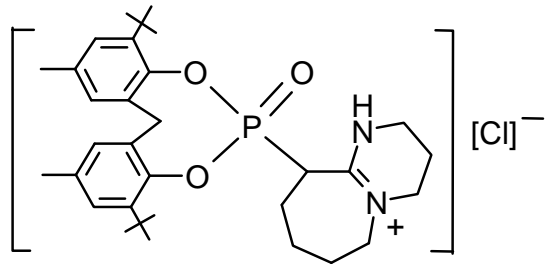

$5[\delta(P): 7.2]$<smiles></smiles>

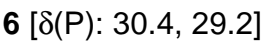

intensity $>85 \%$ ) at $\delta 24.8$ and 31.4 (phosphonate region) in the ${ }^{31} P$ NMR, but a pure compound could not be isolated.

It is important to note that the use of DBU as a base is quite common and several studies using phosphate esters are also conducted in its presence ${ }^{13}$. To our knowledge, in these reports the possibility of formation of phosphonate salts is not mentioned, although it is known that DBU can be lithiated at the $\mathrm{C}(6)$ position (cf. scheme 2 for numbering) ${ }^{14}$. Formation of the phosphonate ( $c f$. 4-6), however, might have taken place via the intermediacy of a phosphoramidate salt VII that undergoes 1,3-proton shift from C-6 to $\mathrm{N}-1$ to give an enamine. This enamine could re- organize to 4 (or 5 or 6) via a cyclic 4-membered transition state involving C-6, C-7, N-8 and P.

Although DBN is also a dinitrogen base similar to DBU, we did not observe a phosphonate salt in reactions using DBN. The reaction of 1 with DBN initially showed peaks at $\delta-3 \cdot 0,-11.4$ and $-12 \cdot 1$ in the ${ }^{31} \mathrm{P}$ NMR. However, the only product that could be isolated in a pure state was the pyrophosphate 7 $[\delta(\mathrm{P})-31 \cdot 1$; this was not present in the original reaction mixture but formed over a period of time]. Even in the reaction using 2, the analogous pyrophosphate $\mathbf{8}$ is a major product. In the reaction of $\mathbf{1}$ with $\mathrm{N}$-methyl imidazole, the pyrophosphate (30\%) along with two other peaks at $\delta-7.0$ and -11.7 are 

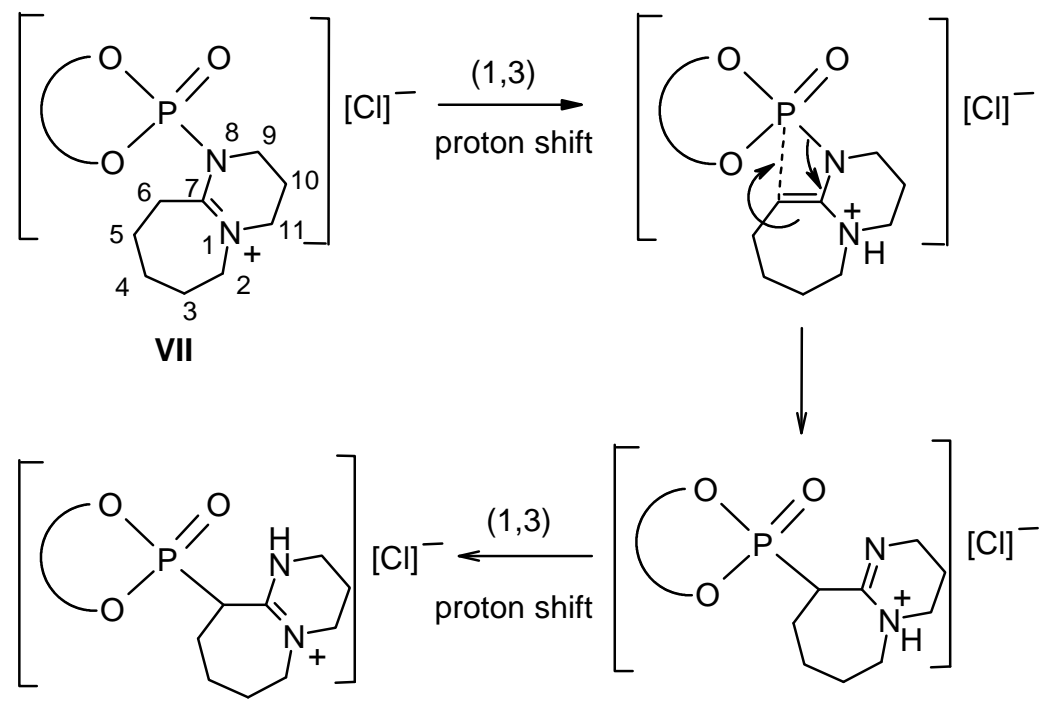

Phosphonate $\mathbf{4 , 5}$ or $\mathbf{6}$

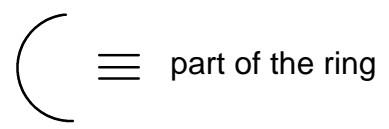

Scheme 2.

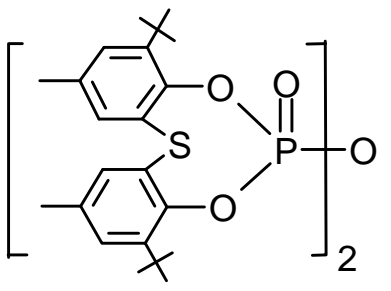

$7[\delta(P):-31.6]$

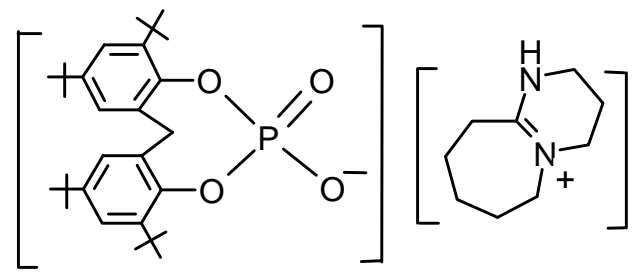

VIII

observed in the ${ }^{31} \mathrm{P}$ NMR. The pyrophosphate is most likely produced by the reaction of the organophosphate salt (formed by the hydrolysis of phosphoramidate salt of type VII) with the chlorophosphate 1 or 2. The ${ }^{31} \mathrm{P}$ NMR peak at $-11.5 \pm 0.2 \mathrm{ppm}$ in the reaction of 1 with DBN or N-methyl imidazole is ascribable to the organophosphate salt $\mathrm{S}(6-t-\mathrm{Bu}-4$ $\left.\left.\mathrm{Me}-\mathrm{C}_{6} \mathrm{H}_{2} \mathrm{O}\right)_{2}\right] \mathrm{P}(\mathrm{O})\left(\mathrm{O}^{-}\right)\left(\mathrm{HBase}^{+}\right)$; for comparison, the
$\delta(\mathrm{P})$ value for the analogous salt $\mathrm{CH}_{2}\left(4,6-(t-\mathrm{Bu})_{2}\right.$ $\left.\left.\mathrm{C}_{6} \mathrm{H}_{2} \mathrm{O}\right)_{2}\right] \mathrm{P}(\mathrm{O})\left(\mathrm{O}^{-}\right)\left(\mathrm{HDBU}^{+}\right)$(VIII) is $-11.4^{15}$.

The ${ }^{31} \mathrm{P}$ NMR peak at $\delta-3 \cdot 0$ or $-7 \cdot 0$ in the reaction of 1 with DBN or N-methyl imidazole respectively, is likely to be due to the expected phosphoramidate salt. This assessment is based on our previous observation that in compounds containing the same eightmembered ring and phosphoryl oxygen, $\mathrm{P}-\mathrm{N}$ bonded compounds show $\delta(\mathrm{P})$ values in between those for $\mathrm{P}-\mathrm{O}$ and $\mathrm{P}-\mathrm{C}$ bonded ones. The peak with $\delta(\mathrm{P})-12 \cdot 1$ (see above) is not assigned.

In the analogous reaction of $\mathbf{3}$ with DBN, several species are formed and the spectrum changed with time. A peak at $\delta-12 \cdot 4$, ascribable to the pyrophosphate, was a major component after 3 days; even with $\mathrm{N}$-methyl imidazole, this compound was the major product $\left[{ }^{31} \mathrm{P} \mathrm{NMR}\right]$.

\subsection{Brief discussion of the structures}

In the structure of 4 (figure 1), the phosphorus is connected to the carbon of the seven-membered ring that is at $\beta$-position to the nitrogen of the sixmembered ring of the DBU residue. The $\mathrm{P}-\mathrm{O}$ bond distances and the angles at phosphorus are in the normal range observed in similar compounds ${ }^{16}$. There is moderately strong hydrogen bonding between the 

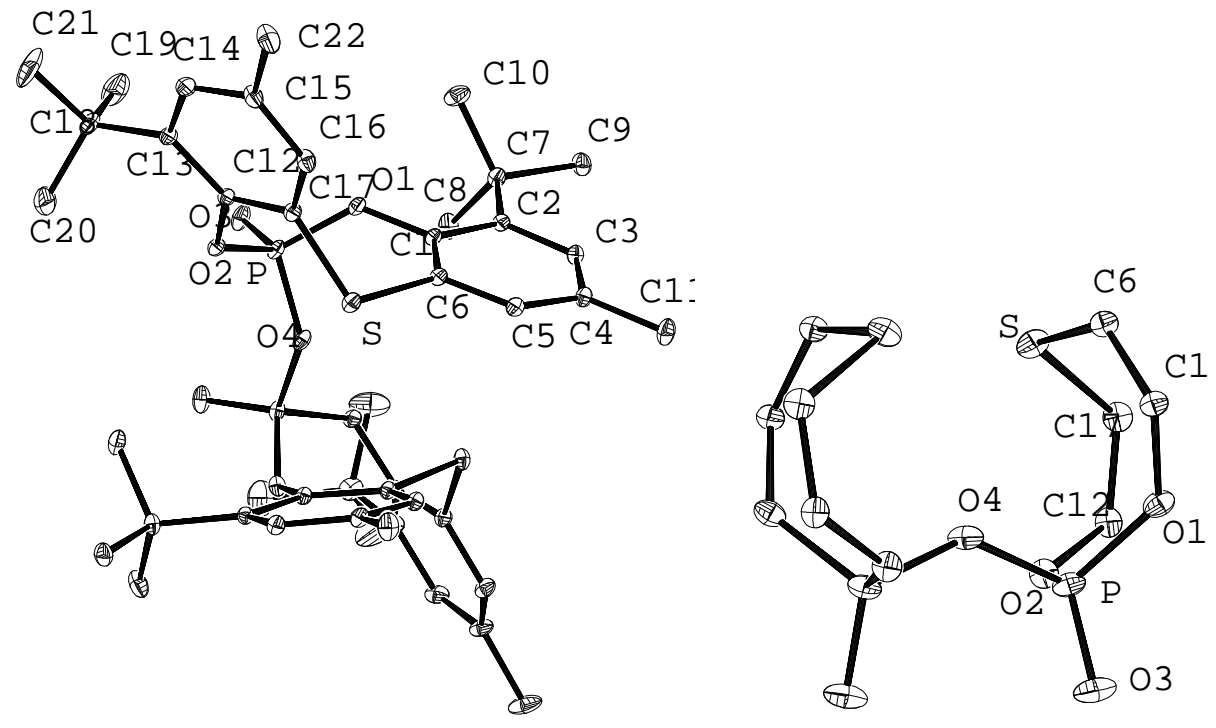

Figure 2. Molecular structure of 7. $\mathrm{CH}_{2} \mathrm{Cl}_{2}$ solvent is not shown. Also shown on the right hand side is the conformation of the eight-membered ring. Selected distances and angles $\left(\AA{ }^{\circ}{ }^{\circ}\right)$ : $\mathrm{P}-\mathrm{O}(3)$ 1.443(2), $\mathrm{P}-\mathrm{O}(1)$ 1.563(2), $\mathrm{P}-\mathrm{O}(2)$ 1.567(2), $\mathrm{P}-\mathrm{O}(4)$ 1.583(1), O(3)-P-O(1) 113.49(11), O(3)-P-O(2) 113.33(10), O(1)-P$\mathrm{O}(2)$ 106.81(9), O(30-P-O(4) 114.68(12), O(1)-P-O(4) 104.06(8), O(2)-P$\mathrm{O}(4) 103 \cdot 47(7), \mathrm{P}-\mathrm{O}(4)-\mathrm{P}^{\prime}$ 134.17(14).

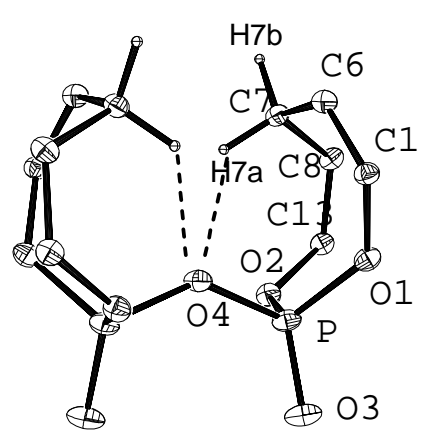

Figure 3. A picture showing the conformation of the phosphocin ring and possible interaction of the $\mathrm{ArCH}_{2}$ hydrogen with the exocyclic non-phosphoryl oxygen in $\mathbf{8}$. Other features are similar to that in 7 ( $c f$. figure 3). Selected distances and angles $\left(\AA,{ }^{\circ}\right)$ : $\mathrm{P}-\mathrm{O}(1) 1.562(4), \mathrm{P}-\mathrm{O}(2)$ 1.563(4), P-O(3) 1.438(4), P-O(4) 1.591(2), O(3)-P$\mathrm{O}(1)$ 113.1(3), O(3)-P-O(2) 114.4(2), O(1)-P-O(2) 106.6(2), $\mathrm{O}(3)-\mathrm{P}-\mathrm{O}(4)$ 115.1(3), O(1)-P-O(4) 103.60(19), O(2)$\mathrm{P}-\mathrm{O}(4)$ 102.83(17), P-O(4)-P' 135.4(4). C(7)-H(7a)...O(4) parameters: $0 \cdot 97,2 \cdot 51,3 \cdot 197(7) \AA, 127 \cdot 5^{\circ}$.

$\mathrm{N}(2)-\mathrm{H}$ and the chloride ion ( $c f$. figure 1). However, the short $\mathrm{N}(1)-\mathrm{C}(28)$ bond distance shows that the double bond is delocalized. The intra-molecular non-bonded P...S distance is $3.33 \AA$ which is less than the sum of van der Waals radii, but longer than that in several hexacoordinate phosphoranes with the same ring residue ${ }^{6,17}$. The eight-membered ring has a tub conformation that is analogous to that observed in many other tetracoordinate phosphorus compounds containing the $\mathrm{CH}_{2}\left(6-t-\mathrm{Bu}-4-\mathrm{Me}-\mathrm{C}_{6} \mathrm{H}_{2} \mathrm{O}\right)_{2}$ $\mathrm{P}(\mathrm{O})$ group, but different from the boat-chair conformation observed for $\mathrm{P}(\mathrm{III})$ compounds with similar rings. In compound 7 ( $c f$. figure 2), the intra-molecular P...S distance is $3.40 \AA$ and the conformation of the eight-membered ring is again $t u b$. Earlier, we had suggested that observation of tub conformation in compounds with the $\mathrm{CH}_{2}\left(6-t-\mathrm{Bu}-4-\mathrm{Me}-\mathrm{C}_{6} \mathrm{H}_{2} \mathrm{O}\right)_{2}$ $\mathrm{P}(\mathrm{O})$ group is related to the presence of weak intramolecular C-H...O interactions between the $\mathrm{ArCH}_{2}$ protons and the phosphoryl oxygen ${ }^{16,18}$ but such a feature is absent in $\mathbf{4}$ or 7 [In the absence of any additional interaction, the expected conformation is that of a boat-chair ${ }^{19}$. The possible intra-molecular $\mathrm{C}-\mathrm{H}$...O contacts in compound $\mathbf{8}$ are shown in figure 3 ; here the bridging oxygen is closer to one of the $\mathrm{ArCH}_{2}$ hydrogens and the conformation of the eight-membered ring is tub. A few more examples are necessary to conclude whether P...S (very weak, if at all) interaction in $\mathbf{4}$ or $\mathbf{7}$ has played a role (or not) in the observed $t u b$ conformation.

An interesting feature in $\mathbf{7}$ is the sulphur-sulphur non-bonded distance of $\approx 4.2 \AA$ within the molecule which suggests that 7 can be used as a soft bidentate ligand towards transition metals. 


\section{Summary}

In this paper we have reported, primarily, the synthesis and structures of (i) the phosphonate $\mathbf{4}$ and (ii) the pyrophosphate 7. The former result, in conjunction with our earlier observations, shows that in the reaction of chlorophosphates with DBU, formation of $\mathrm{P}-\mathrm{C}$ bonded (phosphonate) compound is a major pathway. In the reaction with other bases, one of the major products is always the pyrophosphate ester, formed most likely via phosphoramidate salts. The larger 7-membered ring in DBU, compared to the 5-membered ring DBN, might have brought the $\beta$ (to the nitrogen of the six-membered ring) carbon of this ring in close proximity to the phosphorus resulting in the isolation of phosphonate salts.

\section{Acknowledgements}

We thank (i) the Department of Science and Technology (DST, New Delhi) for setting up a Single Crystal X-ray Diffractometer Facility at the University of Hyderabad and for financial support and (ii) the University Grants Commissions (New Delhi) for equipment under the UPE programme. We also thank Prof. Samudranil Pal for help in the X-ray crystal structure solution of $\mathbf{8}$.

\section{References}

1. Silverberg L J, Dillon J L and Purushotham V 1996 Tetrahedron Lett. 37771
2. Corriu R J P, Lanneau G F and Leclercq D 1989 Tetrahedron 451959

3. Corriu R J P, Lanneau GF and Leclercq D 1986 Tetrahedron 425591

4. Lanneau G F 1986 Phosphorus Sulfur 2750

5. Vijjulatha M, Praveen Kumar K, Kumara Swamy K C and Vittal J J 1998 Tetrahedron Lett. 391819

6. Sherlock D J, Chandrasekaran A, Day R O and Holmes R R 1997 Inorg. Chem. 365082

7. Mukmeneva N A, Kadyrova V Kh, Zharkava V M, Cherkasova D A and Voskresenskaya V O 1986 Zh. Obshch. Khim. 561267

8. Jianguo An, Jeffrey M W, Yi-Zhong An and Wiemer D F 1996 J. Org. Chem. 614040

9. Perrin D D, Armarego W L F and Perrin D R 1986 Purification of laboratory chemicals (Oxford: Pergamon)

10. Senthil Kumar K and Kumara Swamy K C 2004 (to be published)

11. Sheldrick G M 1997 SHELX-97, University of Göttingen, Germany

12. Farrugia L J 1999 J. Appl. Crystallogr. 32837

13. For example, see: Merckling F A and Rüedi P 1996 Tetrahedron Lett. 372217

14. Hermeez I 1987 Adv. Heterocyclic Chem. 4283

15. Vijjulatha M 1998 Synthesis, structure and reactivity of some cyclic phosphorus compounds, $\mathrm{PhD}$ thesis, University of Hyderabad, Hyderabad

16. Kumara Swamy K C, Kumaraswamy S and Kommana P 2001 J. Am. Chem. Soc. 12312642

17. Satish Kumar N, Praveen Kumar K, Pavan Kumar K V P, Kommana P, Vittal J J and Kumara Swamy K C 2004 J. Org. Chem. 691880

18. For a possible $\mathrm{C}-\mathrm{H} \ldots \mathrm{N}$ interaction involving the same ring systems, see: Kommana $\mathrm{P}$, Kumaraswamy $\mathrm{S}$ and Kumara Swamy K C 2003 Inorg. Chem. Commun. 6394

19. Kumaraswamy S, Senthil Kumar K, Raja S and Kumara Swamy K C 2001 Tetrahedron 578181 